\title{
Brentano's Dual-Framing Theory of Consciousness
}

\author{
URIAH KRIEGEL
}

\section{Jean Nicod Institute}

\begin{abstract}
Brentano's theory of consciousness has garnered a surprising amount of attention in recent philosophy of mind (Thomasson 2000, Caston 2002, Hossack 2002, 2006, Kriegel 2003a, 2003b, 2009, Thomas 2003, Smith 2004, Zahavi 2004, Drummond 2006, Textor 2006, 2013). Here I argue for a novel interpretation of Brentano's theory that casts it as more original than previously appreciated and yet quite plausible upon inspection. According to Brentano's theory, as interpreted here, a conscious experience of a tree is a mental state that can be simultaneously thought of, or framed, equally accurately as (i) an awareness of a tree or (ii) an awareness of an awareness of a tree.
\end{abstract}

\section{Brentano's Theory of Consciousness: An Interpretive Puzzle}

The starting point of Brentano's theory of consciousness is the following claim:

(C1) There is no unconscious consciousness. ${ }^{1}$

As Brentano explicitly notes, this is not meant as a tautology (Brentano 1874: I, 143 [102]). But the only way $\mathrm{C} 1$ could be non-tautological is if the two consciousness-terms in it are used in different senses. Oddly, Brentano specifies the two senses only in a footnote:

We use the term 'unconscious' in two ways. First, in an active sense, speaking of a person who is not conscious of a thing; secondly, in a passive sense, speaking of a thing of which we are not conscious. (Brentano 1874: I, 143* [102\$])

The passive sense of 'conscious' may be understood as follows: a mental state $\mathrm{M}$ of a subject $\mathrm{S}$ is conscious $_{\mathrm{p}}$ iff $\mathrm{S}$ is conscious of $\mathrm{M}$. The active sense is rather something like this: a mental state $\mathrm{M}$ of subject $\mathrm{S}$ is conscious $_{\mathrm{a}}$ iff $\mathrm{M}$ is a state of $\mathrm{S}$ 's

Defending this thesis is the mandate of Chapter 2 of Book 2 of Brentano's Psychology from an Empirical Standpoint (Brentano 1874).

2 I quote from the classic 1924 two-volume edition of the Psychology, with references to page numbers of the 1973 edition of the English translation in brackets. I should mention, however, that in most cases I have changed somewhat the translation, in accordance with my own understanding of the original text and with an eye to what comes across as more natural in today's philosophical language (as compared to 1973). 
consciousness. ${ }^{3}$ As Brentano makes clear toward the end of this footnote, the intended reading of $\mathrm{C} 1$ is:

(C2) There is no unconscious consciousness $_{\mathrm{a}}$.

This thesis no longer carries the air of tautology. What it means is that no subject is in a state of consciousness of which she is not conscious. To further dissipate any air of triviality, let us replace one occurrence of a consciousness term with 'awareness' (since Bewusstsein corresponds to both 'consciousness' and 'awareness' in English). We obtain the following thesis:

(C3) For any mental state $\mathrm{M}$ of a subject $\mathrm{S}$, if $\mathrm{M}$ is a state of $\mathrm{S}$ 's consciousness, then $\mathrm{S}$ is aware of $\mathrm{M}$.

I will call this the awareness principle. Brentano's theorizing on consciousness grows out of the awareness principle. (I will conduct the discussion in terms of 'states' and not 'acts' - the latter is Brentano's preferred term-because of the prevalence of state talk in current philosophy of mind. There are of course important differences between states and acts, but they do not affect the goals of this paper.)

Brentano's awareness principle foreshadows what David Rosenthal (2005) calls the 'transitivity principle.' Rosenthal (1986) distinguishes between transitive and intransitive notions of consciousness: transitive consciousness is the property ostensibly designated in such statements as ' $\mathrm{S}$ is conscious of a tree'; intransitive consciousness is the property ostensibly designated in such statements as 'S's thought of the tree is conscious.' With these notions in place, Rosenthal formulates the following principle:

(C*) (Intransitively) conscious states are states we are (transitively) conscious of.

Given relatively straightforward links between the intransitive/transitive and active/passive distinctions, $\mathrm{C} 3$ and $\mathrm{C}^{*}$ amount to the same.

The transitivity principle is the starting point of many modern theories of consciousness, including so-called higher-order perception theories (Armstrong 1968, Lycan 1990), higher-order thought theories (Rosenthal 1990, 2005, Carruthers 2000), and self-representational theories (Kriegel 2003a, 2009, Van Gulick 2006). ${ }^{4}$ All three accept the transitivity principle, but play it out in different ways (see Figure 1 overleaf).

On the higher-order perception model, when $\mathrm{S}$ consciously perceives a tree, $\mathrm{S}$ is in two mental states simultaneously: $\mathrm{M}$, which represents the tree, and $\mathrm{M}^{*}$, which represents $\mathrm{M}$ in a perception-like manner, as through shining a flashlight on $\mathrm{M}$. On the higher-order thought model, $\mathrm{S}$ is in two states as well: $\mathrm{M}$, which represents the tree, and $\mathrm{M}^{*}$, which represents $\mathrm{M}$ in a thought-like manner, as though mentally describing $\mathrm{M}$. On the selfrepresentational model, $\mathrm{S}$ is in one state only, $\mathrm{M}$, which performs double duty as

3 Speaking of a state of consciousness should not be taken to imply that consciousness is a thing whose state is being mentioned. Just as we speak of states of mind without implying that the mind is a thing in the sense that a chair is, so we can speak of consciousness without that implication.

4 It is also rejected, however, by several modern theories of consciousness, notably representationalism (see Dretske 1993). 

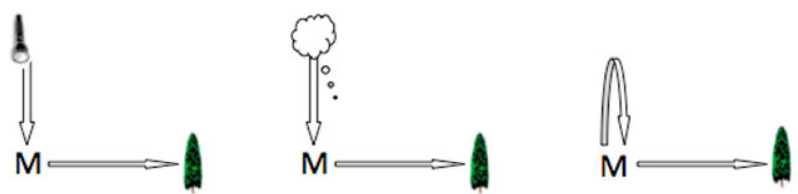

Figure 1. Three models of consciousness

representation of the tree and representation of itself. On all three models, then, it is true that if $\mathrm{M}$ is a state of $\mathrm{S}$ 's consciousness then $\mathrm{S}$ is aware of $\mathrm{M}$. The disagreement is on whether S's awareness of $\mathrm{M}$ is grounded in a distinct perception-like state, distinct thought-like state, or $M$ itself. More generally: $S$ is aware of $M$ in virtue of being in $M^{*}$, but is $\mathrm{M}^{*} \neq \mathrm{M}$ or is $\mathrm{M}^{*}=\mathrm{M}$ ?

It is clear that Brentano takes $\mathbf{M}^{*}$ to be perceptual rather than thought-like. From the earliest chapters of his Psychology from an Empirical Standpoint, Brentano stresses that all conscious states are inner-perceived, and ultimately claims that this demarcates them as mental (1874: I, 128-9 [91-2]). ${ }^{5}$ Accordingly, C3 could be sharpened into the following:

(C4) For any mental state $\mathrm{M}$ of a subject $\mathrm{S}$, if $\mathrm{M}$ is a state of $\mathrm{S}$ 's consciousness, then $\mathrm{S}$ inner-perceives $\mathrm{M}$.

The question is whether conscious states are higher-order-perceived or self-perceived.

Proponents of the self-representational theory of consciousness, which casts a conscious state as identical to the subject's awareness of it, often designate Brentano as a precursor (Caston 2002, Kriegel 2003a). For Brentano clearly insists that a conscious state and the subject's awareness of it are not distinct. Bracketing for present purposes the differences between states and acts, consider the following passage:

In the same mental act in which the sound is present to our minds we simultaneously apprehend the mental act itself. What is more, we apprehend it in accordance with its dual nature insofar as it has the sound as content within it, and insofar as it has itself as content at the same time. (Brentano 1874: 127; my italics)

That is, it is one and the same mental state that constitutes (i) our hearing a trumpet and (ii) our being (inner-perceptually) aware of hearing a trumpet.

Brentano's use of the expression 'the same' in this passage, and of similar locutions in others, has suggested to many that he takes a conscious state and one's awareness of it to be strictly identical. This is what Keith Hossack (2002) calls the 'identity thesis':

The thesis I now wish to consider ... which was endorsed by Brentano, is the claim that any conscious state is identical with knowledge of its own occurrence, and that this is in fact the criterion of whether a state is conscious. (Hossack 2002: 174)

Hossack relies on the following passage from Brentano:

5 It is true that Brentano sometimes describes the inner awareness not as an inner perception (Wahrnehmung), but as an inner presentation (Vorstellung), inner judgment (Urteil), inner cognition/acquaintance (Erkenntnis), or inner consciousness/awareness (Bewusstsein). However, this multiplicity of expressions reflects, for the most part, various substantive views Brentano held about those mental states. 
While we have the presentation of a sound, we are conscious of having it... [T] here is a special connection between the object of inner presentation and the presentation itself, and ... both belong to one and the same mental act. The presentation of the sound and the presentation of the presentation of the sound form a single mental phenomenon (Brentano 1874: I, 176-9 [126-7], quoted in Hossack 2002: 174 fn14).

In the same vein, Brentano-inspired self-representationalists have sometimes formulated the theory in terms of two ideas: when a mental state $M$ is conscious, (1) $M$ is represented by some $\mathbf{M}^{*}$ and (2) $\mathbf{M}^{*}=\mathrm{M}$ (see Kriegel 2003a, Williford 2006).

Observe, however, that the passage Hossack relies on does not quite say that $\mathrm{M}$ and $\mathrm{M}^{*}$ are identical. Instead, Brentano speaks of a 'special connection between,' or rather special interweaving (Verwebung) of, $\mathrm{M}$ and $\mathrm{M}^{*}$. He says that $\mathrm{M}$ and $\mathrm{M}^{*}$ 'belong' to the same mental act, not that they are the same mental act; that they 'form' a single mental phenomenon, not that they are a single mental phenomenon. In other places, Brentano speaks of the 'peculiarly intimate bond (Verbindung) of the mental act $[\mathrm{M}]$ with the accompanying presentation which refers to it [M*]' (1874: I, 187 [133]). He writes:

... the presentation of the sound is connected/bound (verbunden) with the presentation of the presentation of the sound in such a peculiarly intimate (eigentümlich inniger) way that its being at the same time contributes inwardly to the being of the other. (Brentano 1874: I, $179[127])^{6}$

Arguably, if Brentano thought that the 'special' and 'intimate' relation at play was simply the identity relation, he would have put his claims in terms of identity! The fact that he does not may suggest that he thinks there is something more nuanced going on.

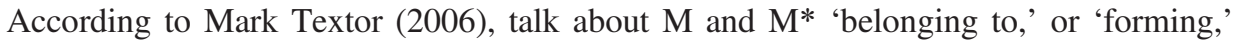
a single mental state suggests a mereological relation: $\mathrm{M}$ and $\mathrm{M}^{*}$ are two parts of a single mental state. We may call this the 'fusion interpretation': a conscious experience of a tree is a mereological fusion of an awareness-of-tree and an awareness-of-awareness-oftree. Textor writes:

If in painting $\mathrm{A}$ and painting A hitting $\mathrm{B}$, I have painted A only once, the two acts of painting cannot be distinct. It seems natural to say that the painting of $\mathrm{A}$ is contained in my painting A hitting B. Similarly, if the sound is not presented twice over, once in the first-order presentation, a second time in the higher-order presentation, the presentations cannot be distinct. The mental acts are interwoven or fused. This should be taken literally. (Textor 2006: 418; my italics)

This more mereological conception of the relationship between $\mathbf{M}$ and $\mathbf{M}^{*}$ is defended by such self-representationalists as Van Gulick (2006) and Kriegel (2009: Ch.6). Brentano often sounds similar, for example when speaking of the 'peculiar fusion (eigentümliche Verschmelzung) of awareness and the object of awareness' (1874: I, 196 [139])

6 I am using here, and in the rest of this paper, a device foreign to the annals of translation: when a key German word is not perfectly captured by any one English word, but is better understood when one contemplates what is common across several English words that may legitimately be taken to render it, I will offer in my translation the several relevant English words, separated by a slash. This is intended to give a better sense of the word's 'living sense.' 
that we find in inner awareness. On this basis, Textor (2006: 422) asserts that Hossack's identity thesis, while perhaps attractive, is simply not Brentano's view.

Over the next four sections, I want to defend the identity interpretation over the fusion interpretation. I proceed in two steps. First, I present a novel interpretation of Brentano's view that casts $\mathrm{M}$ and $\mathrm{M}^{*}$ as, strictly speaking, identical. I will then show why Brentano sometimes uses mereological language to express his particular version of the identity view. The two basic ideas may be put initially as follows:

(1) Brentano holds that a conscious experience of $x$ is a mental state that can be framed, or conceived of, equally accurately as (i) awareness of $x$ or (ii) awareness of awareness of $x$.

(2) Brentano's mereology distinguishes two parthood relations, a real-parthood relation and a conceptual-parthood relation, and the awareness of $x$ and the awareness of the awareness of $x$ are merely conceptual parts of the same state.

The purpose of this paper is to defend and sharpen these two ideas: $\$ 2$ develops the first idea, $\$ 3$ presents Brentano's mereology, $\$ 4$ elaborates on the second idea in light of Brentano's mereology, and $\S 5$ defends the emerging theory of consciousness against substantive objections.

\section{A New Interpretation of Brentano's Theory of Consciousness}

On the interpretation of Brentano's theory I want to offer, a conscious experience of a tree involves the occurrence of a single mental state, but one that lends itself to characterization either as an awareness of a tree or as an awareness of an awareness of a tree. On this interpretation, there is an element of identity cited in Brentano's account as well as an element of difference. The identity pertains to the state itself, the difference pertains to ways of construing the state, or of framing it, or conceptualizing what it is. Nonetheless, at bottom what there is in the subject's mind is a single mental state.

It is natural for us today to articulate this kind of position in terms of Fregean identity. Hesperus and Phosphorus are one entity, but there are two completely separate ways of conceiving of that entity: via the MORNING STAR concept and via the EVENING STAR concept. This is a case of a posteriori identity regarding a concrete particular, but there are also familiar cases of a posteriori identity regarding properties: The concept HEAT and the concept MEAN MOLECULAR ENERGY pick out the same property, but the mere possession of both concepts is not by itself sufficient for realizing this. The way I see things, this is exactly Brentano's position on conscious experience: the awareness of $X$ and the awareness of the awareness of $\mathrm{X}$ are one and the same entity; the concepts, or conceptualizations, AWARENESS OF $\mathrm{X}$ and AWARENESS OF AWARENESS OF $\mathrm{X}$ are distinct ways of picking out that entity. Crucially, both conceptualizations are equally legitimate, indeed equally accurate. When you point at Venus and say 'This is the morning star,' you speak truly, and so do you when you point at Venus and say 'This is the evening star.' By the same token, you speak truly, while 'pointing at' a conscious experience of a tree, either if you say 'This is an awareness of a tree' or if you say 'This is an awareness of an awareness of a tree.' 
Lacking Frege's machinery, I contend, Brentano continuously sought ways of articulating this kind of view. Sometime during the 1880s, he settled on a way of articulating it that involved mereological language; I will discuss this articulation in $\S \S 3-4$. But already in the Psychology one can find passages in which the idea is all but explicit. Consider:

The presentation of the sound $[\mathrm{M}]$ and the presentation of the presentation of the sound $\left[\mathrm{M}^{*}\right]$ form a single mental phenomenon; it is only by considering/regarding/viewing (betrachten) it in its relation to two different objects, one of which is a physical phenomenon and the other a mental phenomenon, that we divide it conceptually [i.e., in thought] into two presentations. (Brentano 1874: I, 179 [127])

In reality, says Brentano, there is only one thing here-the subject's experience. It is just that we can consider or regard it in two different ways, depending on whether we consider it as an intentional relation to a sound or as an intentional relation to an awareness of a sound. Accordingly, the subject's experience can be grasped either qua presentationof-sound or qua presentation-of-presentation-of-sound. But the thing itself is one. (Note that already in this passage Brentano alludes, somewhat cryptically, to a 'conceptual division' of the experience into two presentations. Talk of division, or partition, brings in a mereological dimension as yet undeveloped. We will see its fuller development in Brentano's later writings in §3.2.)

Brentano repeats this formulation in terms of betrachten elsewhere in the Psychology. For example:

... every [conscious state], even the simplest, has [several] aspects (Seite) under which it may be considered/regarded/viewed (betrachtet). It may be considered/regarded/viewed as a presentation of its primary object ...; however, it may also be considered/regarded/ viewed as a presentation of itself... (1874: I, 218-9 [154])

A conscious thought of the Eiffel tower can be viewed as an act of contemplating the Eiffel tower or, just as accurately, as an act of contemplating a contemplation of the Eiffel tower. These are in some sense two different aspects under which the thought can be conceived. But these 'aspects' should not be thought of as separate constituents of the Eiffel-tower thought. Rather, they are different ways one and the same thing can be considered or regarded.

The view is stated particularly straightforwardly by one of Brentano's Enkelschüler ('grand-students'), Hugo Bergmann. Brentano's most ardent follower probably was Anton Marty, who set up a veritable Brentanian orthodoxy in fin-de-siècle Prague. Bergmann was one of Marty's most talented students, and in 1908 he published a remarkable and thoroughly Brentanian study of inner perception. Referring to an act of inner perception as an 'inner act,' he writes:

An inner act $\left[\mathrm{M}^{*}\right]$ and its object $[\mathrm{M}]$ are one and the same (sind eins), and are only conceptually distinguished (beggrifflich unterschieden). (Bergmann 1908: 12)

It is this exact position that I want to ascribe to Brentano. As we will see in $\S 3$, talk of conceptual distinguishability comes directly from Brentano's mereology. 
Call this the Fregean identity interpretation of Brentano's theory of consciousness. According to this interpretation, the point of Brentano's theory may be summarized as follows: if you want to know what a conscious state is, imagine a mental state that lends itself at once to understanding as a presentation of $x$ and to understanding as a presentation of a presentation of $x$. Such a mental state is what a conscious state is. This account of the nature of consciousness is striking in its originality: none of the current theories of consciousness offers quite this perspective on what makes something a conscious state, and to my knowledge, there is no precedent for this view (which I claim to be Brentano's) in the history of Western philosophy.

As such, the view also raises certain immediate question marks. In particular, one might wonder whether there is not something about a conscious state that makes it lend itself to two equally accurate framings, something that grounds this 'dual-framability' of conscious states. If there is not, the view might seem a tad mysterious. But if there is, then the nature of consciousness should be identified rather with that which grounds the dual-framability, whatever that is. We will return to this very real difficulty in $\S 5$. For now, let me only stress that it would be a misunderstanding to take Brentano to simply be making the point that a conscious experience of a tree has both the property of presenting a tree and the property of presenting a presentation of a tree. Rather, his point is that there is no difference between the property of presenting a tree and the property of presenting a presentation of a tree. They are one and the same property, framed in two different ways. It is a crucial part of the view that the multiplicity of potential framings of a conscious experience is not explicable in terms of a multiplicity of properties or components of the experience. On the contrary, it is only by appreciating the fact that one and the same thing - be it a state or a property - admits of two equally good characterizations that we grasp the essence of consciousness. (More on this in §5.)

\section{Brentano's Mereology}

Starting in his 1867 metaphysics lectures at Würzburg and up until his death, Brentano continuously developed systematic ideas about part-whole relations. ${ }^{7}$ Brentano never presented an axiomatic mereological system with proofs of consistency and completeness. But his mereological ideas have influenced directly work in this direction by his students Stumpf (1890), Ehrenfels (1890), Twardowski (1894), and Husserl (1901). ${ }^{8}$ It was a student of Twardowski's, Leśniewski, who first developed a formal system of so-called Classical Mereology (Leśniewski 1916). My approach to the exposition of Brentano's mereology is to first introduce the basics of Classical Mereology and then point out the respects in which Brentano's mereology deviates from it ( 3.1$)$; one deviation is particularly important for our present purposes and will be examined in special depth (§3.2).

7 The first published discussion is the chapter on the unity of consciousness in the Psychology. But more serious developments, partially abstracted from the psychological context, appear in his Vienna lectures from the late 1880s, published posthumously as Chap. 2 of Descriptive Psychology (Brentano 1982). The most systematic and topic-neutral presentation of his mereological ideas published to date is in various dictations from 1908 and 1914-5, collated by Alfred Kastil into Chap. 1 and 2 of The Theory of Categories (Brentano 1933).

$8 \quad$ For more modern studies and developments, see Baumgartner \& Simons (1994) and Baumgartner (2013). 


\subsection{Classical Mereology and Brentano's Mereology}

Classical Mereology (CM) is most naturally axiomatized in terms of six propositions, couched in logical vocabulary plus four mereological notions: part, proper part, overlap, and sum. The four notions are interdefinable, and it is possible in principle to take a single notion and define the others in terms of it (plus the logical vocabulary). Typically mereologists take 'part' as their basic notion, but sometimes they opt for 'proper part' (e.g., Simons 1987). As I find 'proper part' to be the more intuitive notion, I will use it as the basic notion here. We may then say that a part of $\mathrm{A}$ is something which is either a proper part of A or identical to A; A and B overlap when they have a part in common; and the sum of A and B is anything that has A and B as parts such that any other part it has must overlap them. More formally:

$\left(\right.$ Def $\left._{1}\right) \quad \mathrm{A}$ is a part of B iff (i) A is a proper part of B or (ii) A = B.

$\left(\right.$ Def $_{2}$ ) A overlaps B iff there is a C, such that (i) $\mathrm{C}$ is a part of $\mathrm{A}$ and (ii) $\mathrm{C}$ is a part of B.

$\left(\right.$ Def $\left._{3}\right) \quad \mathrm{S}$ is a sum of A and B iff any C that overlaps S overlaps either A or B.

In this construction, we define 'sum' in terms of 'overlap,' 'overlap' in terms of 'part,' and 'part' in terms of 'proper part.' The term 'proper part' remains undefined, a primitive of the system.

The axioms of CM divide into two groups. First are axioms that describe the properparthood relation as a strict partial order (irreflexive, asymmetric, and transitive):

$\left(\mathrm{CM}_{\mathrm{Ar}}\right) \quad \mathrm{A}$ is never a proper part of $\mathrm{A}$.

$\left(\mathrm{CM}_{\mathrm{As}}\right)$ If $\mathrm{A}$ is a proper part of $\mathrm{B}$, then $\mathrm{B}$ is not a proper part of $\mathrm{A}$.

$\left(\mathrm{CM}_{\mathrm{T}}\right)$ If $\mathrm{A}$ is a proper part of $\mathrm{B}$ and $\mathrm{B}$ is a proper part of $\mathrm{C}$, then $\mathrm{A}$ is a proper part of $\mathrm{C}$.

Not every strict partial ordering is proper-parthood, however. So CM includes also three more substantive axioms. One is the axiom of unrestricted composition: for any plurality of things, there is a sum composed of them. Another is the 'axiom of supplementation': if one thing is a proper part of a second, the second must have an additional proper part (to make it whole, so to speak). The last is the 'axiom of extensionality': having the same parts implies being identical and vice versa. More formally:

$\left(\mathrm{CM}_{\mathrm{U}}\right)$ For any plurality of items $\mathrm{A}, \mathrm{B}, \ldots$, there is a $\mathrm{X}$ that is the sum of $\mathrm{A}$, $\mathrm{B}, \ldots$.

$\left(\mathrm{CM}_{\mathrm{S}}\right)$ If $\mathrm{A}$ is a proper part of $\mathrm{B}$, then there is a $\mathrm{C}$, such that (i) $\mathrm{C}$ is a proper part of $\mathrm{B}$ and (ii) $\mathrm{C}$ does not overlap $\mathrm{A}$.

$\left(\mathrm{CM}_{\mathrm{E}}\right) \quad \mathrm{A}=\mathrm{B}$ iff every part of $\mathrm{A}$ is a part of $\mathrm{B}$ and every part of $\mathrm{B}$ is part of $\mathrm{A}$. 
These axioms employ the terms 'sum,' 'part,' and 'overlap,' but can be reformulated entirely in terms of 'proper part' and the logical vocabulary (by using $\operatorname{Def}_{1}-\operatorname{Def}_{3}$ ). As noted, however, CM can also be formulated in terms of six axioms that use only logical vocabulary and 'part.'

So much, then, for CM. How does Brentano's mereology (BM) differ? Brentano explicitly accepts unrestricted composition (Brentano 1933: 5 [16], 11 [19]), and defends the thesis of 'composition as identity' (Brentano 1933: 5 [16], 50 [46]), which is commonly thought to lead rather straightforwardly to the axiom of extensionality. There are two main differences, however, between BM and CM.

One is that in BM the axiom of supplementation does not hold generally (though it does hold for substances, that is, for entities capable of independent existence). The reasons for this odd claim are complex and derive from Brentano's nominalist agenda (see Chisholm 1978, Kriegel 2015). As these issues bear nowise on the interpretation of Brentano's theory of consciousness, here I set them aside. ${ }^{9}$

The most important difference between $\mathrm{CM}$ and $\mathrm{BM}$ concerns the primitive notion of (proper-)parthood. In CM, there is a single, univocal notion at play. This does not seem to be the case for Brentano:

... one may be able to distinguish parts that are actually separable/detachable (ablösbar) from one another, until one reaches parts where such ... separation can no longer take place... . However, even these ultimate actually separate parts, in some sense, can be said to have further parts... . To differentiate these from others, we may refer to them as distinctional parts. (Brentano 1982: 13 [16]; my italics)

Brentano seems to distinguish two types of proper part: separable and distinctional. Here is one example in which they come apart:

Someone who believes in atoms believes in corpuscles which cannot be dissolved into smaller bodies. But even so he can speak of halves, quarters, etc. of atoms: parts which are distinguishable even though they are not actually separable. (Ibid.)

By 'atoms' Brentano means not the entities referred to as atoms in physics, but the entities genuinely admitting of no physical division. A 'physics-atom' with one proton and three electrons does have separable parts, since we can separate the electrons from the proton - this is called 'splitting the atom.' The proton too has separable parts - the quarks making it up. But the electrons have no separable parts. It is impossible to 'split the electron.' Still, even though we cannot separate in reality different parts of electron E, we can distinguish in thought different parts of it. We can call the top half of E 'Jimmy' and the bottom half 'Johnny.' (More precisely, since E has a determinate mass $m$, we can divide $m$ by half and consider each of E's two halves independently.) Jimmy and Johnny are thus distinguishable parts of E, but not separable parts. We may say that they are merely distinguishable parts (Brentano often calls them divisiva).

$9 \quad$ Note, in any case, that for substances (such as Socrates and the Eiffel Tower), the supplementation principle holds: if they have a proper part, then they also have some other proper part that supplements it. In addition, Brentano does accept the axioms of unrestricted composition (Brentano 1933: 16, 19, 45) and extensionality (Brentano 1933: 16, 46). 
It would seem, then, that Brentano distinguishes two notions of (proper-)parthood, which we may call parthood-as-separability and parthood-as-distinguishability. ${ }^{10}$ Accordingly, he recognizes two kinds of (proper) part: separables and distinguishables. The former are separable in reality, the latter are distinguishable in thought. It may well turn out that whatever is separable in reality is distinguishable in thought, but clearly, not everything which is distinguishable in thought is separable in reality - as the electron case shows.

\subsection{Merely Distinguishable Parts}

The notion of merely-distinguishable part does not feature in current mainstream mereology. But many cases appear to suggest it, beside the electron case. Consider the difference between Marie Antoinette's head and Marie Antoinette's smile. There is a sense in which Marie Antoinette's head is part of Marie Antoinette, and there is also a sense in which her smile is a part of her. But these do not seem to be the same sense. Remarkably, Marie Antoinette's head is manifestly a separable part of her, whereas her smile is merely-distinguishable. So one way of making sense of the difference between these two kinds of parthood is in terms of Brentano's separable/distinguishable distinction.

The relationship between a person and her smile is a special case of the more general relation between a 3D object and (any portion of) its 2D surface: the surface cannot be separated from the object and exist on its own. ${ }^{11}$ There is a clear intuition that although it is a genuine part of the object, the surface is such in a different sense from any physically separable component of that object. In general, any $n$-dimensional part of an $n+m$ dimensional object $(n, m>0)$ is intuitively a part of that object in a special sense worth labeling.

There is more than just intuition here, however. There is a real and deep difference between two kinds of part: some parts are ontologically independent of the wholes of which they are parts; others are ontologically dependent. We may mark this difference any way we want, but it is deeper than many other distinctions routinely made in current mereology. One perfectly natural way to mark the difference is to call the former separable parts and the latter merely-distinguishable parts. When $\mathrm{P}$ is a separable part of some whole W, P is ontologically independent of W. For it can exist without W. Accordingly, the destruction of $\mathrm{W}$ does not entail the destruction of $\mathrm{P}$. By contrast, when $\mathrm{P}$ is a merely-distinguishable part of $\mathrm{W}$, it is very much ontologically dependent upon $\mathrm{W}$. Since it cannot be separated from $\mathrm{W}$, it cannot exist without $\mathrm{W}$. The existence of $\mathrm{W}$ is a precondition for its existence. Accordingly, the destruction of $\mathrm{W}$ entails the destruction of P. ${ }^{12}$

10 More accurately: there are at least two notions of parthood. For reasons that will not concern us here, it is natural to read Brentano as distinguishing in fact four notions of parthood (see esp. Brentano 1956: $\S 20.42$ ). For our purposes here, only the central distinction between separable and distinctional parthood will matter.

11 In general, Brentano uses many topological phenomena as examples of distinctional parthood (Brentano 1976). Thus, a boundary between two adjacent regions of space is merely-distinguishable from either region.

12 Here we can see how Husserl's (1901) distinction between pieces and moments is just a rebranding of Brentano's distinction between separable and distinctional parts. Husserl writes: 'Each part that is independent relatively to a whole W we call a Piece (Portion), each part that is non-independent relatively to W we call a Moment (or abstract part) of this same whole W' (Husserl 1901: 29). 
These characteristics of the merely-distinguishable part have clear implications for its ontological status. Brentano tells us that merely-distinguishable parts 'cannot be called realia' (Brentano 1956: 232). In lecture notes from the 1860s, he explicitly contrasts the status of divisiva (i.e., merely distinguishable parts) and 'real beings':

The metaphysical parts, such as bigness, thought, virtue, lions' nature, and so forth are not real beings (wahren Seienden), but rather divisiva. (MS 31534, quoted in Baumgartner 2013: 236, though here I offer my own translation)

What does Brentano mean when he says that merely-distinguishable parts are not 'real beings,' not realia? The answer is far from obvious, but I would propose the following. When we say that $\mathrm{P}$ is a merely-distinguishable part of $\mathrm{W}$, it may seem that ' $\mathrm{P}$ ' is a referring expression picking out some individual item. But in truth, our statement is just an indirect way of describing an aspect of W's structure. It is an infelicitous way of saying that $\mathrm{W}$ is structured P-ly. Thus while the truthmaker of 'The ear is part of Marie's face' consists in a parthood relation between two items, Marie's ear and her face, the truthmaker of 'The smile is part of Marie's face' does not consist in a parthood relation between two items, Marie's smile and her face. Rather, it consists in one item, Marie's face, being structured in a certain way, that is, in Marie's face being smiley. From this perspective, the point of the notion of a merely-distinguishable part, for Brentano, is to recognize that a thing may have no (separable) parts and yet have structure. It is not simple in the sense of being structureless, even though it is simple in the sense of being (in reality) partless. These are two different and non-coextensive kinds of simplicity.

Consider: when we say that Marie is two-legged, what makes our statement true is that Marie has two separable parts each of which is a leg; but when say that Marie is smiling, something must make this statement true as well, even though Marie does not have any separable part which is a smile. That is, even though there are no such entities as smiles, we speak truly when we say that Marie is smiling. Moreover, this is a truth cum fundamentum in re-there is something about Marie (something about the structure of her face) that makes it true. Talk of merely-distinguishable parts is a device for describing this structure. More generally, it is a device for describing structure-withoutseparable-parts. But we must keep in mind that since merely-distinguishable parts are by definition distinguishable only in thought, what there is in reality is just the structure: although parts are more fundamental than structure when it comes to separable parts, structure is more fundamental than parts when we are dealing with merely-distinguishable parts.

It might be objected that Brentano's notion of a merely-distinguishable part is still unmotivated, on the grounds that Brentano imposes on us parthood talk where property talk would do just fine. The atom has the property of having a mass (or occupying a space) divisible by half, Marie Antoinette has the property of smiling, a 3D object has the property of having a 2D surface, and so on. Merely-distinguishable parthood is thus entirely dispensable.

For Brentano, however, the important thing is that in conscious experience, there is no real distinction between awareness of $x$ and awareness of awareness of $x$-whatever ontological category we slot awareness under. So even if we speak of the property of being an awareness of $x$ and the property of being an awareness of an awareness of $x$, Brentano would claim that these are in reality one and the same property. And yet in 
thought we can discern in that property two 'dimensions,' or 'aspects,' or indeed merelydistinguishable parts... Thus it appears that the role played by the notion of merely-distinguishable part is needed whether we think of awareness in terms of states or in terms of properties. ${ }^{13}$

\section{The Mereology of Consciousness}

Brentano's distinction between separable and merely-distinguishable parts means that when he uses mereological language to express his view of consciousness, there are two very different things he might have in mind. In saying that an awareness of $x$ and an awareness of an awareness of $x$ are parts of a single mental state, he might have in mind (a) that they are separable parts of some 'greater' whole, or (b) that they are merely-distinguishable parts of a single thing.

In the Psychology, the distinction between the two parthood relations is nowhere explicitly drawn. But where it is drawn - in lecture notes from the late 1880s, at leastBrentano is explicit that parthood-as-distinguishability is what connects an experience $\mathrm{M}$ and the awareness of it $\mathrm{M}^{*}$. He speaks of

... the inseparable connection/fusion (untrennbar Verbindung) of a primary $[\mathrm{M}]$ and a concomitant $\left[\mathrm{M}^{*}\right]$ mental reference (psychischen Beziehung). Every consciousness, upon whatever object it is primarily directed [e.g., a tree], is concomitantly directed at itself [the experience of the tree]. (Brentano 1982: 22 [25]; my italics)

In describing the connection between $\mathrm{M}$ and $\mathrm{M}^{*}$ as inseparable, Brentano intimates mere-distinguishability. This becomes more explicit further along, where Brentano considers the internal unity of an audiovisual experience. Imagine having the audiovisual experience of a loud airplane flying overhead. We may distinguish three parts in this experience: (i) the visual awareness of the airplane's shape and color, (ii) the auditory awareness of the airplane's sound, and (iii) the inner awareness of the overall experience. Brentano holds that while (i) and (ii) are separable from each other, (i) and (iii) are merely-distinguishable, as are (ii) and (iii). ${ }^{14}$ The contrast is clear:

Whereas the separation of parts considered there [the auditory and visual parts] can only be actual, the parts considered here [the visual part and the inner-awareness part] can only be separated distinctionally. This is why, having referred to the former as actually

13 In addition, even if the distinguishable-part role could be played by properties, for Brentano the more important fact is that the property role can be played by parts! Because of his nominalism, Brentano needs to be able to say everything he wants to say without ever mentioning properties. More accurately, he needs to paraphrase truths whose truthmakers ostensibly involve a property as constituent into truths whose ostensible truthmakers do not. Thus, he wants to find a truthmaker for 'There is a smile on Marie Antoinette's face' that does not involve the property of having a smile as constituent. His way of doing this is to recognize Marie Antoinette's smile as a merely-distinguishable part of Marie. In Kriegel (2015), I show how Brentano's mereological innovations allow him to handle a wider array of apparent truths without invoking properties.

14 This may not have been Brentano's view in the Psychology, where, in discussing the unity of consciousness, he describes the auditory and visual parts of an audiovisual experience as divisives of a single state. By 1890 , it is clear that he uses 'divisive' and 'distinctional part' to mean the same thing. It may be that Brentano later sharpened his notion of a divisive, and in the Psychology it would still intended rather vaguely to pick out a special kind of part, or it may be that he changed his substantive commitments on the relationships between the auditory and visual parts. 
separable mental parts, it is probably not wholly inappropriate to call the latter inseparable (distinctional) parts. (1982: 25 [27]; my italics)

In an audiovisual experience, the auditory aspect and the visual aspect are ontologically independent. If while looking at the airplane you suddenly went deaf, your visual experience would persist without the auditory component; if you instead suddenly went blind, the auditory experience would persist without the visual component. But for Brentano, there is no conceivable event that could bring apart your visual experience and your awareness of your visual experience, or your auditory experience and your awareness of it. These are merely distinguishable parts of a single underlying reality.

Recall now that while separable parts can be separated in reality, merely-distinguishable parts can only be distinguished in thought. They do not have any individual existence in reality. It is only conceptually, or in thought, that we can pull them apart. If so, when we say that an awareness-of-tree $M$ and an awareness-of-awareness-of-tree $M^{*}$ are merely-distinguishable, it would seem to follow that $\mathbf{M}$ and $\mathbf{M}^{*}$ are not two separate items in reality; it is only in thought that we can pull them apart. More specifically, it is only in thought that we can pull an awareness-of-tree apart from the overall conscious experience of the tree, and at the same time, it is only in thought that we can pull an awareness-of-awareness-of tree apart from that experience. Neither the awareness-of-tree nor the awareness-of-awareness-of tree can exist on its own. The destruction of the experience entails the destruction of the awareness-of-tree, as it does the destruction of the awareness-of-awareness-of tree.

My suggestion can be summarized as follows, then: all Brentano has in mind, when using mereological language to describe the relationship between $M$ and $M^{*}$, is that in a single, simple, and indivisible mental state, one can distinguish in thought $\mathrm{M}$ and one can likewise distinguish in thought $\mathrm{M}^{*}$. There is no claim about real separability, that is, of parthood-in-reality. There is only a claim about different ways the one simple thing in reality can be thought of. This is perfectly consistent, then, with the Fregean identity interpretation of Brentano's theory of consciousness. For it suggests precisely that awareness-of-tree and awareness-of-awareness-of-tree are simply two different ways of thinking of a single mental state.

On the Fregean identity interpretation defended here, Brentano holds that $\mathrm{M}$ and $\mathrm{M}^{*}$ are merely-distinguishable parts of a single mental state. What this means, I have suggested, is that in reality there is only one thing, but we can think of it, or regard it, in two different ways. Just as Venus can be thought of, equally legitimately, as the morning star or as the evening star, a tree experience can be thought of, equally legitimately, as an awareness of a tree or as an awareness of an awareness of a tree.

On this interpretation, it is natural to say that the awareness-of-tree and the awarenessof-awareness-of-tree are not numerically distinct, because in reality they are one and the same thing. To repeat, this is not meant as the idea that a conscious state has both the property of being an awareness of some object and the property of being an awareness of an awareness of that object; rather, it is meant as the idea that in a conscious state, the property of being an awareness of an object and the property of being an awareness of an awareness of that object are one and the same. The difference is only in how that one property is regarded. At the same time, we are missing something if we just assert that conscious experience involves the subject being in a single mental state, or the subject instantiating a single relevant property, and leave it at that. What we are missing, 
moreover, is the definitive aspect of conscious experience - the way it envelops awareness and awareness-of-awareness in a single mental state. We might therefore say, doubtless somewhat impressionistically, that qua regarded the awareness and the awarenessof-awareness are different, even though in and of themselves they are identical. Compare a single duck-rabbit drawing. If we do not see two potential book covers here-one suitable for The Ugly Duckling and the other appropriate for The Tales of Peter Rabbit-we are missing something. Likewise, we can frame the conscious state as $\mathbf{M}$ or frame it as $\mathrm{M}^{*}$, and these are different framings.

This explains, I suggest, why Brentano stresses in some contexts the non-distinctness of $\mathrm{M}$ and $\mathrm{M}^{*}$ and in others their non-identity. When designing a cover for The Ugly Duckling or The Tales of Peter Rabbit, we would stress the difference between the duck drawing and the rabbit drawing. But when the bill for the copyright fees arrives, we might stress sameness, arguing that we only used one drawing. Likewise, in the context of discussing the internal structure of a conscious state (e.g., in Chap. 3 and 4 of Book 2 of the Psychology), Brentano stresses the difference between the state's various distinguishable parts $\left(\mathrm{M}\right.$ is not the same distinguishable part as $\mathrm{M}^{*}$ ); but in discussing the threat of infinite regress (e.g., in Chap. 2 of Book 2 of the Psychology), Brentano stresses the sameness of the state itself.

It is in this light that we should understand passages that appear to underline the nonidentity of $\mathrm{M}$ and $\mathrm{M}^{*}$. Consider this example:

... it is clear that such a real identity never holds between our concurrent mental activities, and that it will never be found between the diverse aspects of the simplest act which were differentiated earlier... They are divisives of the same reality, but that does not make them really identical with it and thus with one another. (Brentano 1874: I, 229 [161])

Textor (2006: 423) relies on this passage to argue for the implausibility of the identity interpretation - as well he should, given the explicit denial of identity in the passage. I would suggest, however, that Brentano is trying, in such passages, to highlight the difference between a conscious state qua awareness of a tree and a conscious state qua awareness of awareness of a tree. Anyone who simply stated that there is just one mental state here, and left it at that, would be missing the crucial feature of conscious states - the fact that they lend themselves to conceptualization in two very different yet equally accurate ways. It is this kind of opponent, who does not even recognize the sense in which conscious states essentially involve awareness-of-awareness, that Brentano has in his sight in passages such as this.

This Fregean-identity interpretation is more flexible than either Hossack's flatter identity interpretation or Textor's fusion interpretation. In expounding his identity interpretation, Hossack (2002) appears to make no provision for the mereological subtleties of Brentano's account (although see Hossack 2006 for some distancing from the straight-up identity interpretation). In defending the fusion interpretation, Textor (2006) explicitly recognizes that $\mathrm{M}^{*}$ is a divisive (i.e., a merely-distinguishable part) of $\mathrm{M}$. What he fails to recognize, however, is that this means there is only one mental state involved. Textor says that "A "divisive" is an object that can be distinguished in another object as a part, although it cannot be separated from it' (Textor 2006: 423). This seems to directly contradict Brentano's own treatment of parts of a conscious whole as merely apparent parts: 
Brentano tells us that these 'constitute apparent-parts/part-appearances (Teilphänomene) of a mental phenomenon, the elements of which are neither distinct things nor parts of distinct things' (1874: I, 232 [164]). Saying that a divisive is 'part of another object' suggests that what we have on our hands here are two different items, the conscious state and its awareness-of-awareness part; yet as we have seen for Brentano there is in reality only one item. The inner perception of a tree perception is not a part of another state, that of perceiving a tree. Thus just as Hossack's identity interpretation has difficulties making sense of fusion-leaning passages (see esp. Brentano 1874: I, 228-9 [161]), Textor's fusion interpretation has difficulties making sense of the identity-leaning passages (see esp. 1874: I, 179-80 [127]). The interpretation presented here makes sense of both. It is, strictly speaking, an identity interpretation, but one that mobilizes a fuller understanding of Brentano's mereology to do justice to mereological-sounding passages.

\section{Brentano's Theory of Consciousness Revisited}

Higher-order and self-representational theories are motivated by the intuitiveness of the awareness principle: conscious states are states we are aware of having. It has proven difficult, however, to accommodate the principle (and its intuitiveness) without incurring structural problems in one's theory.

Higher-order theories face a dilemma. They must construe the higher-order state they invoke either as conscious or as unconscious. If they construe it as unconscious, they cannot account for the intuitiveness of the awareness principle: it is unclear why conscious states should immediately strike us as states we are aware of if the relevant awareness is but a sub-personal event (and why the awareness principle should be intuitive if conscious states do not immediately strike us as states we are aware of). But if the higher-order state is construed as conscious, an infinite regress immediately ensues: the higher-order state would have to be conscious in virtue of being targeted by a yet higher-order state (since it is itself a state the subject is aware of), which would have to be targeted by a further higher-order state, and so on.

Self-representational theories attempt to circumvent the regress problem by claiming that one is aware of one's conscious state in virtue of being in that very conscious state itself. Since that state represents itself, and is conscious, the state is consciously represented - which explains the intuitiveness of the awareness principle. However, self-representationalists face a different dilemma. Not all properties of a phenomenally conscious state are themselves phenomenally conscious: my experience's property of occurring on a Wednesday, for example, contributes nothing to what it is like for me to have the experience. Presumably, self-representationalists would say that a state's phenomenal properties are those which the state represents itself as having. But then a question arises: does the conscious state represent only its non-representational properties or also its representational ones? If it represents only its non-representational properties, it is unclear why the state's directedness at the outside world is phenomenally manifest. If it represents also its representational properties, we are off on a regress again: the state would have to represent its self-representing, and then represent its so representing, and so on. An infinite regress of states is avoided, but an infinite regress of representational properties replaces it.

Within Brentano's framework, the problem is much less pressing. The worst-case scenario would be an infinite regress of accurate ways of conceiving of a conscious state- 
plainly a less troubling prospect, all told, than an infinite regress of states or properties. In truth, however, it is unclear that any kind of regress attends the Brentanian picture. The view is that a conscious state is a single state which lends itself to framing both as awareness-of- $x$ and as awareness-of-awareness-of- $x$. But there is no discernible pressure to invoke some third-order awareness-of-awareness-of-awareness-of- $x$ to illuminate the fact that the conscious state lends itself to a second-order framing as awareness-of-awareness-of- $x$.

In the extant literature, perhaps the most persistent challenge to higher-order theories is that surrounding the 'division of phenomenal labor.' In general, mental states can misrepresent - and that in two ways: (i) by misrepresenting something to have properties it does not in reality have, or (ii) by misrepresenting something to exist that in reality does not. The same applies to the higher-order states that target conscious states: nothing prevents the occurrence of a higher-order state with the content $<\mathrm{I}$ am having a reddish experience $>$ when in reality (i) one is having a greenish experience, or even when (ii) one is having no relevant experience at all. It was originally argued that higher-order theories lead to paradoxical results whatever they choose to say about such cases (Byrne 1997, Neander 1998, Levine 2001: Chap. 3, Caston 2002, Kriegel 2009: Chap. 4). More recently, it has also been argued that the problem applies with equal force to self-representational theories (Weisberg 2008, 2011, Picciuto 2011). Bracketing the plausibility of such arguments, it is clear that they do not apply to Brentano's theory. For according to him, there is only one thing in reality, without any division of labor between a first-order representation and a higher-order or self-representation. Some experiences can be accurately framed both as a reddish perception and as an inner perception of a reddish perception. Others can be accurately framed both as greenish perception and as inner perception of greenish perception. But there is simply no experience which can be accurately framed both as a reddish perception and as an inner perception of a greenish perception. ${ }^{15}$

Rosenthal (1990) once argued that Brentano's theory is incoherent when it comes to conscious desires. For a mental state cannot be both a desire and an awareness of a desire. This is because desire involves a world-to-mind direction of fit whereas awareness involves a mind-to-world direction of fit. According to Rosenthal, a single mental state cannot have both directions of fit at once. However, the principle that a single mental state cannot involve both directions of fit is entirely unsupported. When $\mathrm{S}$ is glad that $p$, $\mathrm{S}$ presumably both desires that $p$ and believes that $p$. If gladness can involve both directions of fit, then conscious desire can as well. (For longer discussion, see Kriegel 2003b.)

Some objections to Brentano's theory can be handled in light of his notion of merelydistinguishable parts. Zahavi (2004) and Drummond (2006), for example, have pressed the following Husserlian complaint against Brentano's theory of consciousness: if a conscious experience of a tree performs double duty as a perception of the tree and a perception of a perception of the tree, the tree would appear in consciousness twice. Now, Brentano himself insists that the tree appears only once in consciousness:

We have recognized that the seeing and the presentation of the seeing are connected/ bound (verbunden) in such a way that the color, as the content of the seeing, at the same

\footnotetext{
15 Accordingly, no gap can open up between the reality of an experience's phenomenal character and its appearance in inner perception, that is, the phenomenal character it in fact has and the one it inner-perceptually appears to have.
} 
time contributes to/constitutes (beträgt) the content of the presentation of the seeing. The color, therefore, even though it is presented both in the seeing and in the presentation of the seeing, is still presented only once. (Brentano 1874: I, 188-9 [134])

The Husserlian complaint, presumably, is that nothing entitles Brentano to say this. However, there very clearly is something that entitles Brentano to say this, namely, his distinction between separable and distinguishable parts, and his claim that the perception of the tree and the perception of the perception of the tree are merely-distinguishable. The tree qua showing up in M's content and the tree qua showing up in $\mathrm{M}^{*}$ 's content are one and the same-even though that one tree can be regarded in different ways (as perceived and as perceived to be perceived).

The very appeal to the separable/distinguishable distinction may be questioned, though. In particular, it might well be asked: what is the point of insisting on distinguishing different aspects of a single entity in thought, if the entity has no parts in reality? Indeed, if a thing has no parts in reality, distinguishing in it parts in thought would appear to be in some sense nonveridical or inappropriate. To my knowledge, Brentano nowhere addresses this worry. As noted in $\$ 3.2$, however, his basic motivation for the notion of a merely-distinguishable part appears to be to recognize that a thing may have no (separable) parts and yet have structure. And thoughts (and statements) about that structure can be veridical (or true); it is just that they must be properly understood-as indirectly concerned with structure.

This relates to what is perhaps the deepest objection to Brentano's theory of consciousness (as interpreted here). Granted that a conscious state is a state that lends itself to framing either as an awareness of $x$ or as an awareness of an awareness of $x$, we may ask what it is about the conscious state that makes it so lend itself. This creates a dilemma for Brentano: either he can cite something in the state itself that grounds its dual-framability or he cannot. If he can, then whatever he cites should be taken to constitute the essence of consciousness, preempting the dual-framability feature. If he cannot cite anything, then the theory ends up being quite mysterian: we are left with an inexplicable oddity in the midst of the natural world.

As before, Brentano does not address this issue anywhere. But if we apply the general point just made about the relationship between merely-distinguishable parts and structure, we obtain the following response to the dilemma. On the one hand, we must recognize that both 'This experience involves awareness of a tree' and 'This experience involves awareness of an awareness of a tree' are true cum fundamentum in re. This means that there definitely is something about the experience that makes it 'dually framable' - a certain intrinsic structure that grounds its lending itself to two equally accurate framings. We can use talk of merely-distinguishable parts to describe this structure. At the same time, in the case of merely-distinguishable parts, structure is more fundamental than them. Brentano's basic idea, then, would seem to be that, at bottom, there is no way to characterize what the structure of a conscious experience is other than by saying that it is the kind of structure which licenses a characterization both as awareness-of- $x$ and as awareness-of-awareness-of- $x$, that is, the kind of structure that may be described in terms of the merely-distinguishable parts awareness-of- $x$ and awareness-of-awareness-of- $x$. From this perspective, it is only by successfully wrapping our minds around the notion of a mental state which is equally awareness of $x$ and awareness of awareness of $x$ that we can understand the special structure characteristic of conscious state. This is a 
cognitive achievement without which one cannot successfully grasp the nature of consciousness. ${ }^{16,17}$

\section{References}

Armstrong, D.M. 1968. A Materialist Theory of the Mind. New York: Humanities Press.

Baumgartner, W. 2013. 'Franz Brentano's Mereology.' In D. Fisette and G. Fréchette (eds.), Themes from Brentano. Amsterdam: Rodopi. and P. Simons 1994. 'Brentano's Mereology.' Axiomathes 1: 55-76.

Bergmann, H. 1908. Untersuchungen zum Problem der Evidenz der Inneren Wahrnehmung. Halle: Max Niemeyer.

Brentano, F.C. 1874. Psychology from Empirical Standpoint. Trans. A.C. Rancurello, D.B. Terrell, and L.L. McAlister. London: Routledge, 1973.

1911. 'Appendix to the Classification of Mental Phenomena.' English trans. in Brentano (1874).

1930. The True and the Evident. Ed. O. Kraus. Trans. R.M. Chisholm, I. Politzer, and K. Fischer. London: Routledge, 1966.

1933. The Theory of Categories. Ed. A. Kastil. Trans. R.M. Chisholm and N. Guterman. The Hague: Martinus Nijhoff, 1981.

1956. Die Lehre vom richtigen Urteil [The Theory of Correct Judgment]. Bern: Francke.

1976. Philosophical Investigations on Space, Time and the Continuum. Ed. S.

Körner and R.M. Chisholm. Trans. B. Smith. London: Croom Helm, 1988.

1982. Descriptive Psychology. Ed. R.M. Chisholm and W. Baumgartner. Trans. B.

Müller. London: Routledge, 1995.

Byrne, D. 1997. 'Some Like It HOT: Consciousness and Higher Order Thoughts.' Philosophical Studies 86: 103-129.

Carruthers, P. 2000. Phenomenal Consciousness. Cambridge: Cambridge University Press.

Caston, V. 2002. 'Aristotle on Consciousness.' Mind 111: 751-815.

Chisholm, R. 1978. 'Brentano's Conception of Substance and Accident.' Grazer Philosophische Studien 5: 197-210.

Dretske, F.I. 1993. 'Conscious Experience.' Mind 102: 263-283.

16 There is a kind of effort involved in this exercise - an effort not unlike the one we make, say, when we try to wrap our minds around quantum indeterminacy. We may first resist accepting it at face value, attempting to explain the apparent indeterminacy in terms of hidden variables, say. But when eventually the gambit fails, we have to stretch our minds in one way or another, exercising a special kind of theoretical imagination, to grasp a fundamentally and ultimately indeterminate world.

This work was supported by the French National Research Agency's grants ANR-11-0001-02 PSL* and ANR-10-LABX-0087. For comments on a previous draft, I am grateful to Anna Giustina, Vincent Grandjean, Nicola Spinelli, and Ken Williford. I have also benefited from presenting drafts of this paper at École Normale Supérieure, Kings' College London, LOGOS, the University of Houston, the University of Liege, the University of Texas-Austin, and the University of Warwick. I am grateful to the audiences there, in particular Oliver Black, Bill Brewer, Géraldine Carranante, Bob Hale, Denis Seron, Mark Textor, Josh Weisberg, and Ken Williford. In addition, I have benefited from exchanges with Alexandre Billon, Arnaud Dewalque, Steven Gubka, Robert Koons, Leon Leontyev, Cathal O'Madagain, Katherine Piatti, Simon Prosser, François Recanati, Peter Simons, Gianfranco Soldati, and Sebastian Watzl. 
Drummond, J.J. 2006. 'The Case(s) of (Self-)Awareness.' In U. Kriegel and K. Williford (eds.), Self-Representational Approaches to Consciousness. Cambridge MA: MIT Press.

Ehrenfels, C. von. 1890. 'Über “Gestaltqualitäten”.' Vierteljahrsschrift für wissenschaftliche Philosophie 14: 249-292. Reprinted as 'On Gestalt Qualities.' Trans. B. Smith. In. B. Smith (ed.), Foundations of Gestalt Theory. Munich and Vienna: Philosophia Verlag.

Hossack, K. 2002. 'Self-Knowledge and Consciousness.' Proceedings of the Aristotelian Society 102: 163-181.

Hossack, K. 2006. 'Reid and Brentano on Consciousness.' In M. Textor (ed.). The Austrian Contribution to Analytic Philosophy. London: Routledge.

Husserl, E. 1901. Logical Investigations II. Trans. J.N. Findlay. London: Routledge, 2001.

Kriegel, U. 2003a. 'Consciousness as Intransitive Self-Consciousness: Two Views and an Argument.' Canadian Journal of Philosophy 33: 103-132.

— 2003b. 'Consciousness, Higher-Order Content, and the Individuation of Vehicles.' Synthese 134: 477-504.

2009. Subjective Consciousness: A Self-Representational Theory. Oxford and New York: Oxford University Press.

2015. 'Thought and Thing: Brentano's Reism as Truthmaker Nominalism.' Philosophy and Phenomenological Research 91: 153-180.

— Cambridge, MA: MIT Press.

Lesniewski, S. 1916. 'Foundations of the General Theory of Sets,' Trans. D.I. Barnett. In his Collected Works, Ed. S.J. Surma, J. Srzednicki, D.I. Barnett and F.V. Rickey. Dordrecht: Kluwer, 1992.

Levine, J. 2001. Purple Haze: The Puzzle of Consciousness. Oxford and New York: Oxford University Press.

Lycan, W.G. 1990. 'Consciousness as Internal Monitoring.' Philosophical Perspectives 9: $1-14$.

Neander, K. 1998. 'The Division of Phenomenal Labor: A Problem for Representational Theories of Consciousness.' Philosophical Perspectives 12: 411434.

Picciuto, V. 2011. 'Addressing Higher-Order Misrepresentation with Quotational Thought.' Journal of Consciousness Studies 18: 109-136.

Rosenthal, D.M. 1986. 'Two Concepts of Consciousness.' Philosophical Studies 49: 329-359.

1990. 'A Theory of Consciousness.' ZiF Technical Report 40, Bielfield, Germany. Reprinted in N.J. Block, O. Flanagan, and G. Guzeldere (eds.), The Nature of Consciousness. Cambridge, MA: MIT Press, 1997.

1993. 'Thinking that One Thinks.' In M. Davies and G. W. Humphreys (eds.), Consciousness: Psychological and Philosophical Essays. Oxford: Blackwell.

2004. 'Varieties of Higher-Order Theory.' In R.J. Gennaro (ed.), Higher-Order Theories of Consciousness. Amsterdam: John Benjamins.

2005. Consciousness and the Mind. Oxford: Oxford University Press.

Simons, P.M. 1987. Parts. Oxford: Oxford University Press. 
Smith, B. 1988. 'Gestalt Theory: An Essay in Philosophy.' In B. Smith (ed.), Foundations of Gestalt Theory. Munich and Vienna: Philosophia Verlag.

Smith, D.W. 2004. 'Return to Consciousness.' In his Mind World: Essays in Phenomenology and Ontology (ed.), Cambridge: Cambridge University Press.

Stumpf, C. 1890. Tonpsychologie II. Leipzig: Hirzel.

Textor, M. 2006. 'Brentano (and some Neo-Brentanians) on Inner Consciousness.' dialectica 60: 411-432.

2013. 'Brentano on the Dual Relation of the Mental.' Phenomenology and the Cognitive Sciences 12: 465-483.

Thomas, A.P. 2003. 'An Adverbial Theory of Consciousness.' Phenomenology and the Cognitive Sciences 2: 161-185.

Thomasson, A.L. 2000. 'After Brentano: A One-Level Theory of Consciousness.' European Journal of Philosophy 8: 190-209.

Twardowski, K. 1894. On the Content and Object of Presentations. Trans. R. Grossmann. The Hague: M. Nijhoff, 1977.

Van Gulick, R. 2006. 'Mirror Mirror-is that All?' In Kriegel and Williford (2006).

Weisberg, J. 2008. 'Same Old, Same Old: The Same-Order Representational Theory of Consciousness and the Division of Phenomenal Labor.' Synthese 160: 161-181.

2011. 'Misrepresenting Consciousness.' Philosophical Studies 154: 409-433.

Williford, K.W. 2006. 'The Self-Representational Structure of Consciousness.' In Kriegel and Williford (2006).

Wodehouse, H. 1909. 'Knowledge as Presentation.' Mind 18: 321-329.

Zahavi, D. 2004. 'Back to Brentano?' Journal of Consciousness Studies 11: 66-87. 